\title{
Comparative analysis of novel and conventional Hsp90 inhibitors on HIF activity and angiogenic potential in clear cell renal cell carcinoma: implications for clinical evaluation
}

Jessica ES Bohonowych', Shuping Peng², Udhayakumar Gopal', Michael W Hance', Shane B Wing ${ }^{3}$, Kelley M Argraves ${ }^{3}$, Karen Lundgren ${ }^{4}$ and Jennifer S Isaacs $^{1 *}$

\begin{abstract}
Background: Perturbing Hsp90 chaperone function targets hypoxia inducible factor (HIF) function in a von HippelLindau (VHL) independent manner, and represents an approach to combat the contribution of HIF to cell renal carcinoma (CCRCC) progression. However, clinical trials with the prototypic Hsp90 inhibitor 17-AAG have been unsuccessful in halting the progression of advanced CCRCC.

Methods: Here we evaluated a novel next generation small molecule Hsp90 inhibitor, EC154, against HIF isoforms and HIF-driven molecular and functional endpoints. The effects of EC154 were compared to those of the prototypic Hsp90 inhibitor 17-AAG and the histone deacetylase (HDAC) inhibitor LBH589.

Results: The findings indicate that EC154 is a potent inhibitor of HIF, effective at doses 10-fold lower than 17-AAG. While EC154, 17-AAG and the histone deacetylase (HDAC) inhibitor LBH589 impaired HIF transcriptional activity, CCRCC cell motility, and angiogenesis; these effects did not correlate with their ability to diminish HIF protein expression. Further, our results illustrate the complexity of HIF targeting, in that although these agents suppressed HIF transcripts with differential dynamics, these effects were not predictive of drug efficacy in other relevant assays. Conclusions: We provide evidence for EC154 targeting of HIF in CCRCC and for LBH589 acting as a suppressor of both HIF-1 and HIF-2 activity. We also demonstrate that 17-AAG and EC154, but not LBH589, can restore endothelial barrier function, highlighting a potentially new clinical application for Hsp90 inhibitors. Finally, given the discordance between HIF activity and protein expression, we conclude that HIF expression is not a reliable surrogate for HIF activity. Taken together, our findings emphasize the need to incorporate an integrated approach in evaluating Hsp90 inhibitors within the context of HIF suppression.
\end{abstract}

\section{Background}

Hypoxia inducible factor (HIF) is a master regulator of the hypoxic response and plays a critical role in the development and progression of numerous solid cancers $[1,2]$. HIF functions as a heterodimeric transcription factor composed of an oxygen regulated $\alpha$-subunit and a constitutively expressed $\beta$-subunit (or ARNT). HIF activity is tightly regulated by oxygen tension wherein

\footnotetext{
* Correspondence: isaacsj@musc.edu

'Department of Cell and Molecular Pharmacology, Medical University of South Carolina, Charleston, SC, USA

Full list of author information is available at the end of the article
}

its activity is restrained under oxygenated conditions via von-Hippel Lindau (VHL) ubiquitin ligase mediated degradation of the $\alpha$ subunit [3]. In contrast, tumor hypoxia facilitates HIF- $\alpha$ stabilization, dimerization, and transcriptional activation. HIF regulates a multitude of genes that contribute to pro-tumorigenic processes including invasion, angiogenesis and therapeutic resistance [2,4-6]. Importantly, inhibition of HIF function suppresses tumor formation and progression, and restores treatment sensitivity, highlighting HIF as a clinically relevant therapeutic target $[1,7]$.

\section{C) Biomed Central}

(C) 2011 Bohonowych et al; licensee BioMed Central Ltd. This is an Open Access article distributed under the terms of the Creative Commons Attribution License (http://creativecommons.org/licenses/by/2.0), which permits unrestricted use, distribution, and reproduction in any medium, provided the original work is properly cited. 
Clear cell renal cell carcinoma (CCRCC) tumors are highly vascularized and among the most lethal kidney tumors [8]. CCRCC, with its defined loss of VHL function and resulting constitutive HIF expression and activity, is a useful model to decipher the role of HIF in cancer progression and to evaluate HIF targeting strategies. Although the sufficiency of HIF for CCRCC remains somewhat controversial [9], HIF is a major participant in CCRCC within the context of VHL loss [10-13]. Of the two main pro-tumorigenic HIF- $\alpha$ isoforms, HIF- $2 \alpha$ elicits tumor formation in CCRCC xenograft models $[10,14]$ and appears to be more commonly upregulated in CCRCC relative to HIF-1 $\alpha$ [4]. However, HIF-1 $\alpha$ driven CCRCC xenograft models have also been documented [15], as well as compensatory mechanisms between the two isoforms [16]. Therefore, the targeting of both HIF isoforms may represent the most effective therapeutic approach. In spite of this, few studies have addressed the ability of candidate agents to target both isoforms.

A number of generalized HIF targeted approaches have been employed, including modulation of HIF expression, transcription, translation, dimerization, transactivation, and stability [17-23]. Small molecule inhibitors of the chaperone heat shock protein 90 (Hsp90) represent a growing class of clinically utilized anti-tumorigenic agents that have been collectively exploited as an alternative means of targeting HIF- $\alpha$, given their shared ability to disrupt the ATP dependent chaperone activity of Hsp90 and block the protein folding of respective Hsp90 clients. HIF is an Hsp90 client protein [24] and we, and others, have shown that perturbing Hsp90 function with geldanamycin (GA) and small molecule derivatives promotes HIF- $1 \alpha$ and HIF$2 \alpha$ protein degradation and suppression of transcriptional activity [25-27]. Importantly, Hsp90 targeted approaches bypass the requirement for both VHL and oxygen, instead utilizing the ubiquitin ligase RACK1 $[25,28]$. Therefore, these agents hold promise in tumor environments where VHL function is compromised, as in CCRCC or tumor hypoxia. In support of this premise, the Hsp90 inhibitors GA, 17-(allylamino)-17-demethoxygeldanamycin (17-AAG or Tanespimycin) and 17dimethylaminoethylamino-17-demethoxygeldanamycin (17-DMAG or Alvespimycin) demonstrate anti-tumorigenic and anti-angiogenic properties in both in vitro and in vivo animal models, due in part to their ability to inhibit HIF function [29-33]. However, despite the promising pre-clinical actions of these inhibitors, clinical trials with 17-DMAG have been relatively unsuccessful for CCRCC and other solid tumors [34-36]. These failures highlight the critical need to further evaluate the effects of Hsp90 targeting agents upon HIF dependent signaling and angiogenesis in CCRCC and other cancers.
Since the advent of 17-AAG, numerous Hsp90 inhibitors exhibiting enhanced potency and diminished toxicity have been developed [37-41], leaving open the possibility that these next generation agents may demonstrate increased potency and efficacy in vivo. In addition to these direct Hsp90 inhibitors, histone deacetylase (HDAC) inhibitors, such as the clinically utilized LBH589 (Panobinostat), indirectly inhibit Hsp90 through protein hyperacetylation, leading to loss of chaperone function [42-44] and comparable inhibition of a subset of Hsp90 client proteins [45-47]. Similar to Hsp90 inhibitors, HDAC inhibitors ablate HIF levels and activity in several models [42,45,48-50]. Although one report examined the effects of HDAC inhibition upon HIF-1 expression in CCRCC cells [50] and another utilized LBH589 in combination with rapamycin [15], an analysis of these agents upon HIF-2 expression or activity is lacking, an important oversight given that a majority of CCRCC tumors preferentially express HIF-2 [4]. Moreover, no reports have directly compared the effects of ATP based competitive Hsp90 inhibitors with HDAC inhibitors such as LBH589 with respect to their respective ability to suppress the activity of HIF isoforms.

In this study, we utilized a prototypic next generation Hsp90 inhibitor, EC154, representing a novel synthetic compound with enhanced potency and diminished toxicity relative to 17 -AAG. EC154 is a compound with improved properties (potency, pharmacokinetic and pharmacodynamic) over BIIB021, the first oral synthetic Hsp90 inhibitor to reach clinical trials [51]. EC154 binds to the Hsp90 ATP binding site in a manner similar to EC144 [52]. Towards the goal of identifying more potent HIF targeting agents, we evaluated the ability of 17 AAG, EC154, and LBH589 to suppress HIF activity and angiogenic potential in CCRCC cells. We show herein that although these agents exert inhibitory effects against HIF activity, they exhibited differential time and dose dependent responses not consistently linked to relative HIF protein expression. Our results therefore provide valuable guidance on the use of these agents as HIF inhibitors and highlight the biological complexity of Hsp90 inhibition upon suppression of HIF activity and downstream targets. Further, our results suggest that the evaluation of HIF expression in tissues as a surrogate for therapeutic efficacy may not suffice as a reliable indicator of HIF suppression.

\section{Methods}

\section{Reagents and antibodies}

The Hsp90 inhibitors 17-(Allylamino)-17-demethoxygeldanamycin (17-AAG) and EC154 were provided by the NCI Developmental Therapeutics Program and Biogen IDEC, respectively. The HDAC inhibitor LBH589 was provided by Dr. Peter Atajda (Novartis). HIF-1 $\alpha$ (100- 
$105)$ and HIF-2 $\alpha$ (100-122) antibodies were from Novus Biologicals. Additional antibodies included GAPDH (9295) from Sigma; RACKI (17754) and topoisomerase II (13059) from Santa Cruz; P-ERK ${ }_{\mathrm{T} 202 / Y 204}$ (4370), ERK (4695), P-src Y416 $_{4}$ (2101), src (2108) from Cell Signaling; and P-FAK $\mathrm{Y}_{397}$ (44-624G) and FAK (AHO-0502) from Invitrogen.

\section{Cell culture}

UMRC2 and 786-O cells were provided by Dr. M.I. Lerman and Dr. R. Klausner (NCI, National Institutes of Health). UMRC2-VHL replaced cells were made as previously described [25] and 786-O VHL-replaced cells were provided by Dr. W.G. Kaelin (Dana-Farber Cancer Institute). All CCRCC cell lines were maintained in buffered Dulbecco's modified Eagle's medium (Thermo Scientific) supplemented with $10 \%$ fetal bovine serum (Gibco), L-glutamine (Thermo Scientific), and penicillin/ streptomycin (Mediatech). Human umbilical vascular endothelial cells (HUVEC) were purchased from Invitrogen and maintained in Medium 200/LSGS (Gibco). All cells were maintained at $37^{\circ} \mathrm{C}$ and $5 \% \mathrm{CO}_{2}$

\section{Western blots}

Nuclear preparations were prepared as previously described [25]. Briefly, cells were washed in phosphatebuffered saline, collected using a hypotonic buffer (20 $\mathrm{mM}$ HEPES, $5 \mathrm{mM} \mathrm{MgCl}_{2}, 5 \mathrm{mM} \mathrm{NaCl}, 1 \mathrm{mM}$ EDTA, $\mathrm{pH}$ 7.9) containing protease inhibitors (Roche), nuclear pellets were collected following addition 10\% Nonidet P4, lysed in hypertonic buffer (20 mM HEPES, $400 \mathrm{mM}$ $\mathrm{NaCl}, 1 \mathrm{mM}$ EDTA) containing protease inhibitors, and supernatant collected. For whole cell lysates, cells were washed with phosphate-buffered saline, incubated in lysis buffer (20 mM Tris pH 7.5, $150 \mathrm{mM} \mathrm{NaCl}, 1 \%$ NP40, 1 mM EDTA) containing protease inhibitors, and supernatant collected. All protein concentrations were determined by BCA method (Thermo Scientific).

\section{qRT-PCR analysis}

CCRCC cells were treated with 17-AAG, EC154, LBH589 or DMSO solvent control. Total RNA was extracted with the RNeasy Kit (Qiagen, Valencia, CA). Total RNA $(1 \mu \mathrm{g})$ was used for reverse transcription with SuperScript ${ }^{\circledR}$ III First-Strand Synthesis SuperMix for qRT-PCR (Invitrogen,) and resulting cDNA was used as a template for quantitative Real-time PCR analysis. The ratio of GLUT1, VEGF, LOX1 and OCT-4 to $\alpha$ tubulin was measured with real-time-quantitative PCR (iQ5 Multicolor Real-Time PCR Detection System, BioRad Laboratories, Hercules, CA) using iQ5 optical system software. The reaction mixture contained $12.5 \mu \mathrm{l}$ SYBR green mix (Bio-Rad), $2 \mu \mathrm{l}$ of mixed primers, and 2 $\mu \mathrm{l}$ cDNA template. The final volume was adjusted with
$\mathrm{H}_{2} \mathrm{O}$ to $25 \mu \mathrm{l}$. Annealing temperature was $55^{\circ} \mathrm{C}$ for all reactions. Fluorescent products were measured by a single acquisition mode after each cycle. Primers are as follows: $\alpha$-tubulin: F-AACGTCAAGACGGCCGTGT, RGACAGAGGCAAACTGAGCAC; GLUT1: F-GTGGGC ATGTGCTTCCAGTA, R-ACAGAACCAGGAGCACAGTGAA; VEGF: F-AGGCCAGCACATAGGAGAGA, R-TTTCCCTTTCCTCGAACTGA; CAIX: F-GGGTGT CATCTGGACTGTGTT, R-CTTCTGTGCTGCCTTC TCATC; qLOXI: F-ATGAGTTTAGCCACTTGTACC TGCTT, R-AAACTTGCTTTGTGGCCTTCA; OCT-4: F-GACAACAATGAGAACCTTCAG GAGA, R-CTGGC GCCGGTTACAGAACCA.

\section{Lentiviral infection and luciferase reporter assays}

The Cignal Lenti-HIF Reporter system (SABiosciences) was used to stably transduce CCRCC cells with constitutively expressed renilla luciferase and HIF-regulated firefly luciferase constructs. UMRC2 and 786-0 cells were grown to $60-70 \%$ confluence and infected for $24 \mathrm{~h}$ according to the manufacturer's specifications. Cells were placed under puromycin selection and positive clones were expanded. For analysis of HIF activity, cells at $70 \%$ confluency were treated for $16 \mathrm{~h}$ with or without inhibitors, lysed, and dual luciferase activity analyzed (Promega). Experiments were performed in triplicate and arbitrary values normalized to renilla luciferase levels.

\section{Immunoassays}

UMRC2 and 786-O cells were pre-treated for $4 \mathrm{~h}$ with the indicated compounds in low serum (3\% FBS) medium. Cells were rinsed with PBS and then incubated with freshly prepared treatments in similar medium for $16 \mathrm{~h}$ under or normoxia or hypoxia (1\% $\mathrm{O}_{2}$ ). Conditioned medium was collected following brief centrifugation and whole cell lysate was collected as described. VEGF and uPA concentrations were measured by ELISA (R\&D Systems) according to the manufacturer's instructions, and normalized to total protein concentration of the conditioned medium.

\section{Tubule formation assay}

HUVEC cells were serum starved overnight $(0.1 \%$ M200) and plated (15,000 cells/well) in 96-well plates pre-coated with $50 \mu \mathrm{L}$ of phenol-red free growth factor reduced Matrigel (BD Biosciences) with the indicated treatments. CCRCC conditioned medium was collected and added to HUVEC cells for $6 \mathrm{~h}$. Effects on angiogenesis were determined by quantifying branch points in 6 replicate wells ( 1 field per well; 40X) for each treatment and are presented as percent of untreated control with standard deviation. 


\section{Cell migration}

Cell migration was assessed using Boyden chambers (0.8 $\mu \mathrm{m}$; BD Biosciences). Cells were plated into the upper chamber in reduced serum DMEM $(0.1 \%)$ with complete DMEM in the lower chamber and indicated agents added to both chambers. At $24 \mathrm{~h}$, inserts were washed with PBS, the non-motile cells removed with cotton swabs, and the migratory cells fixed in formaldehyde, visualized with $0.1 \%$ crystal violet, and counted. The data presented represent the mean value from 4 replicates per treatment.

\section{Cell viability}

CCRCC cells $(5,000)$ were plated in 96-well plates, treated with 17-AAG, EC154, LBH589 or vehicle for $16 \mathrm{~h}$ and assessed for cell viability using the Cell-Titer Blue Reagent as per the manufacturer's instructions (Promega).

\section{Electrical Cell Substrate Impedance Sensing Assay (ECIS)}

Changes in endothelial cell monolayer permeability were determined using the well established method of measuring electrical impendence [53]. HUVECs were seeded onto ECIS 8W10E+electrode arrays (Applied Biophysics, Troy, NY) precoated with human plasma fibronectin (Invitrogen) at $100 \mu \mathrm{g} / \mathrm{mL}$ in $0.15 \mathrm{M} \mathrm{NaCl}$, $0.01 \mathrm{M}$ Tris, $\mathrm{pH}$ 8.0. Transendothelial electrical resistance (TEER), an index of endothelial cell barrier function, was measured using an ECIS Model 1600 instrument (Applied Biophysics, Troy, NY). Cells were allowed to form a confluent monolayer and cell barrier until a plateau was reached ( $\sim 3$ days). In order to evaluate the ability of 17-AAG to reverse the effects of agents known to disrupt barrier function, culture medium was replaced with fresh EGM-2 containing the barrier disruptor, VEGF $(50 \mathrm{ng} / \mathrm{mL})$ in the absence or presence of 17-AAG $(1 \mu \mathrm{M})$, and impedance was measured every $5 \mathrm{~min}$ at $15 \mathrm{kHz}$ frequency. In order to evaluate the effects of CCRCC conditioned medium (CM) on endothelial cell barrier function, culture medium was replaced with $\mathrm{CM}$ collected for $24 \mathrm{~h}$ from $1 \times$ $10^{6}$ UMRC2 or 786-0 cells in the absence or presence of 17-AAG (1 $\mu \mathrm{M})$, EC154 (100 nM), or LBH589 (100 nM). HUVEC-CM was used as a control for possible nutrient depletion. The traces shown represent the mean of duplicate wells for each treatment.

\section{Statistical analysis}

Statistical significance was determined using one-way ANOVA followed by one-tailed student's T-tests. IC50 values were calculated using SigmaPlot10 (Systat) wherein curves were fitted to either a 3-parameter logistical or 4-parameter sigmoidal plot $\left(R^{2}=0.695-0.996\right)$.

\section{Results}

Differential effects of inhibitors upon HIF protein expression are isoform and cell context dependent Given the prominent tumorigenic role of HIF in the majority of solid tumors, it is critically important to include evaluation of this metric when evaluating the efficacy of novel next generation Hsp90 inhibitors. To begin to address this question, we performed a comprehensive evaluation of the effects of 17-AAG, EC154, and LBH589 upon cellular HIF- $1 \alpha$ and HIF- $2 \alpha$ protein expression and activity in UMRC2 cells which express both HIF- $1 \alpha$ and HIF- $2 \alpha$ proteins and 786-O cells, which express only the HIF- $2 \alpha$ isoform [54,55]. All three agents reduced HIF-1 $\alpha$ expression in UMRC2, with EC154 more effective than 17-AAG, and LBH589 almost completely eliminating HIF- $1 \alpha$ expression (Figure 1). Interestingly, the HIF- $2 \alpha$ expression in 786-O cells was refractory to these treatments. Equally unexpectedly, LBH589 elicited a reproducible increase in HIF- $2 \alpha$ expression in both $786-\mathrm{O}$ and UMRC2 cells. In contrast to the effects in 786-O, 17-AAG and EC154 reduced HIF- $2 \alpha$ expression in UMRC2, indicating that the effects of these drugs upon HIF isoforms may be cell context dependent. It has been shown that the VHL independent Hsp90 mediated destruction pathway for HIF-1 $\alpha$ utilizes the adaptor protein RACK1 [28]. Given the apparent insensitivity of HIF- $2 \alpha$ protein in response to Hsp90 inhibition, we examined the relative levels of RACK1 in these cell lines. As shown in Figure 1, RACK1 expression was abundant in both cell lines and was unaffected by drug treatment, indicating that sufficient RACK1 was available to mediate HIF- $\alpha$ degradation. Therefore, the mechanism for the sustained HIF$2 \alpha$ protein stability in 786-O cells following Hsp90 inhibition remains to be further clarified.

\section{Comparative effects of inhibitors upon HIF transcriptional activity}

To correlate HIF protein expression with HIF activity following drug exposure, we next evaluated HIF target gene levels by qRT-PCR. Dose curves at $16 \mathrm{~h}$ treatments were used to determine the most efficacious concentration for each drug (Additional file 1: Figure S1), and these optimal concentrations were utilized for all further studies $(1 \mu \mathrm{M}$ 17-AAG, 100 nM EC154, and 100 nM LBH589). VHL replaced derivatives were included as a relative negative control for HIF activity. The co-expression of both HIF- $\alpha$ isoforms in UMRC2 cells [55], coupled with the potential ability of the suppression of one HIF isoform to modulate expression and activity of the remaining protein [56-58], present challenges in evaluating the effects of these inhibitors upon HIF-1 and HIF-2 function. To address this question, we selected five transcripts, two of which are 


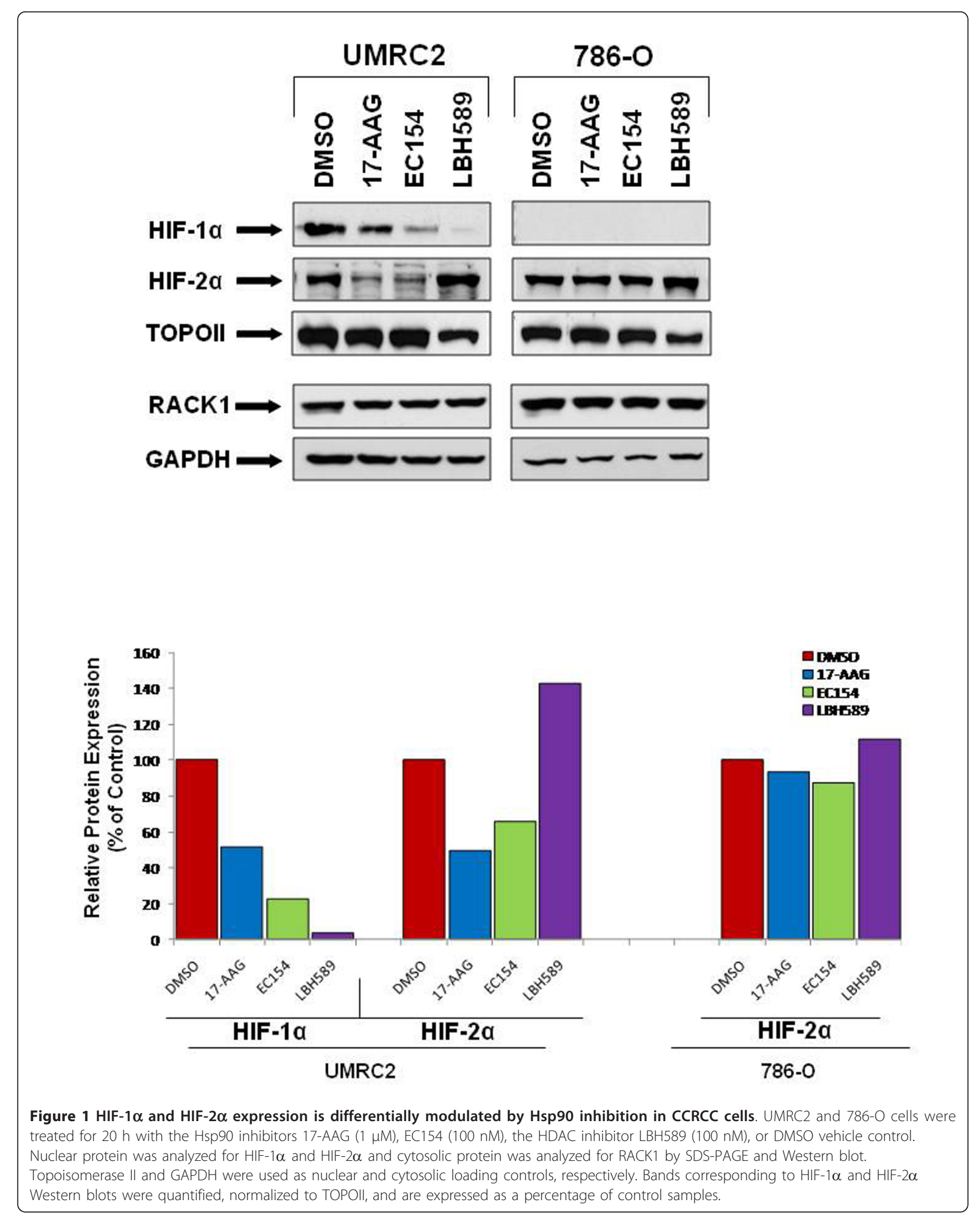


preferentially regulated by HIF-1 $\alpha$ (CAIX, LOX1), two by HIF-2 $\alpha$ (GLUT1, OCT-4), and one influenced by both isoforms $(V E G F)$. As shown in Figure 2, all three drugs significantly inhibited mRNA expression of the selected transcripts in UMRC2, with LBH589 exhibiting the most profound suppression, comparable to VHL replaced cells. This result also indicates that the LBH-589 mediated increase in HIF- $2 \alpha$ expression did not elicit a comparable increase in HIF-2 $\alpha$ activity. Although CAIX and VEGF appeared to be more resistant to suppression in EC154 treated cells, this trend was not observed in subsequent experiments (Figure 3). The effect of these agents in 786$\mathrm{O}$ was generally more modest when compared to UMRC2, although the general trends were mirrored, with 17-AAG demonstrating enhanced suppression of HIF driven transcripts when compared with EC154 (Additional file 1: Figure S1). Although $C A I X$ and $L O X-1$ are reported to be controlled by HIF- 1 activity $[59,60]$, the apparent suppression of these transcripts following drug treatments in 786$\mathrm{O}$ indicates that HIF- $2 \alpha$ may also influence their transcriptional regulation.

The clinical administration of therapeutic agents results in a dynamic response largely influenced by concentration flux and gradients within the tumor. Our data in Figure 2 indicate that HIF targets exhibit differential sensitivity to these agents, a finding that may profoundly influence in vivo drug efficacy and contribute to dynamic responses. To more carefully analyze this parameter, we examined the time-dependent effects of these agents over a period of 2-16 h. As shown in Figure 3, all three inhibitors elicited a time dependent suppression of HIF regulated transcripts, as well as variable kinetics. CAIX transcript levels were more refractory to suppression by 17-AAG in both cell lines at earlier time points, while the remaining HIF transcripts in UMRC2 cells demonstrated a rapid and maximal suppression by $2 \mathrm{~h}$. In 786-O cells, VEGF message was refractory to inhibition at earlier time points. With EC154 treatment, CAIX exhibited earlier suppression, while VEGF message was refractory at earlier time points in both cell lines. Although EC154 mediated suppression of transcripts occurred with slower kinetics, the overall extent of suppression at later time points was comparable to that observed with 17-AAG. Interestingly, LBH589 demonstrated the most potent suppression of transcripts in UMRC2, while 786-O transcripts were more refractory by comparison. Part of the complexity observed with HIF driven transcripts may be due to additional signaling pathways and effectors that contribute to their regulation [61-63] as supported by the differential expression of these transcripts in VHL replaced 786-O cells (Additional file 1: Figure S1).

\section{Comparative effects of inhibitors upon VEGF promoter activity and VEGF secretion}

To uncouple some of this complexity and to evaluate the specific effects of these agents upon HIF-dependent transcription, we utilized a HIF-driven luciferase reporter assay system in UMRC2 and 786-O cells. Consistent with our qRT-PCR results, both $17-\mathrm{AAG}$ and EC154

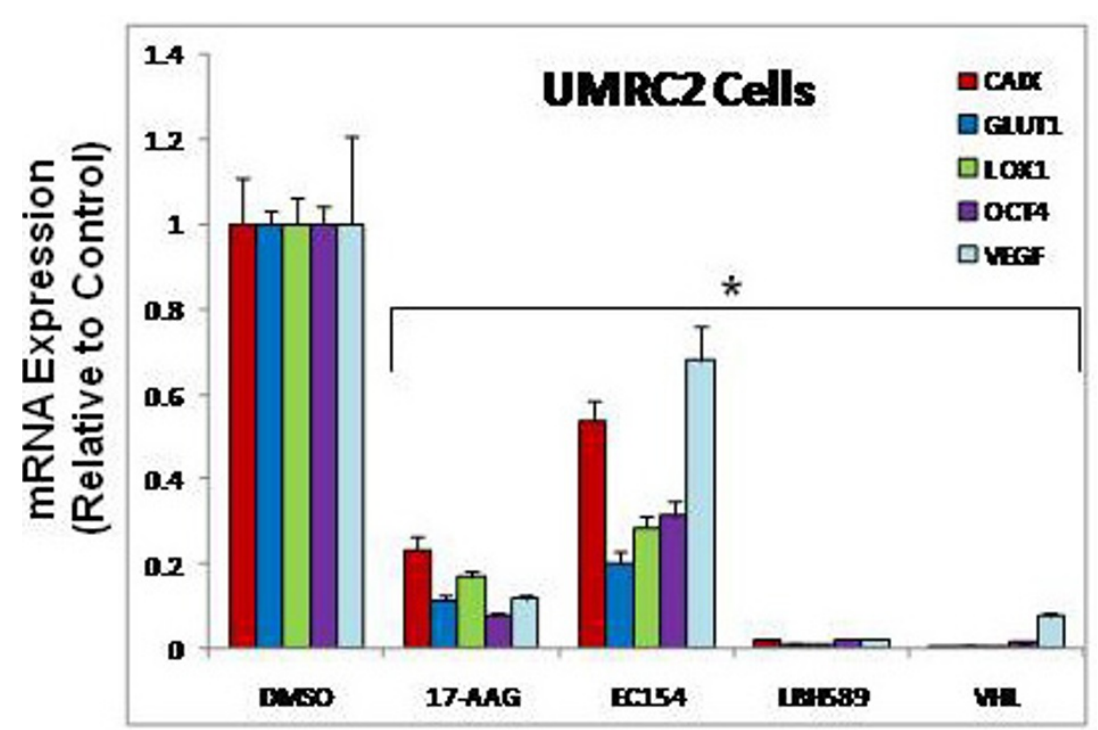

Figure 2 The inhibitors 17-AAG, EC154, and LBH589 inhibit HIF-dependent gene transcription in CCRCC cells. The CCRCC cell line UMRC2 was treated for $16 \mathrm{~h}$ with inhibitors as in Figure 1. Total mRNA was isolated and HIF- $\alpha$ regulated genes analyzed by qRT-PCR. Values were normalized to GAPDH and are presented relative to control cells, with standard deviation shown. All drug treatments significantly reduced all transcript levels $\left(^{*}\right)$ as determined by ANOVA and Student's $t$-test $(p<0.05)$. 


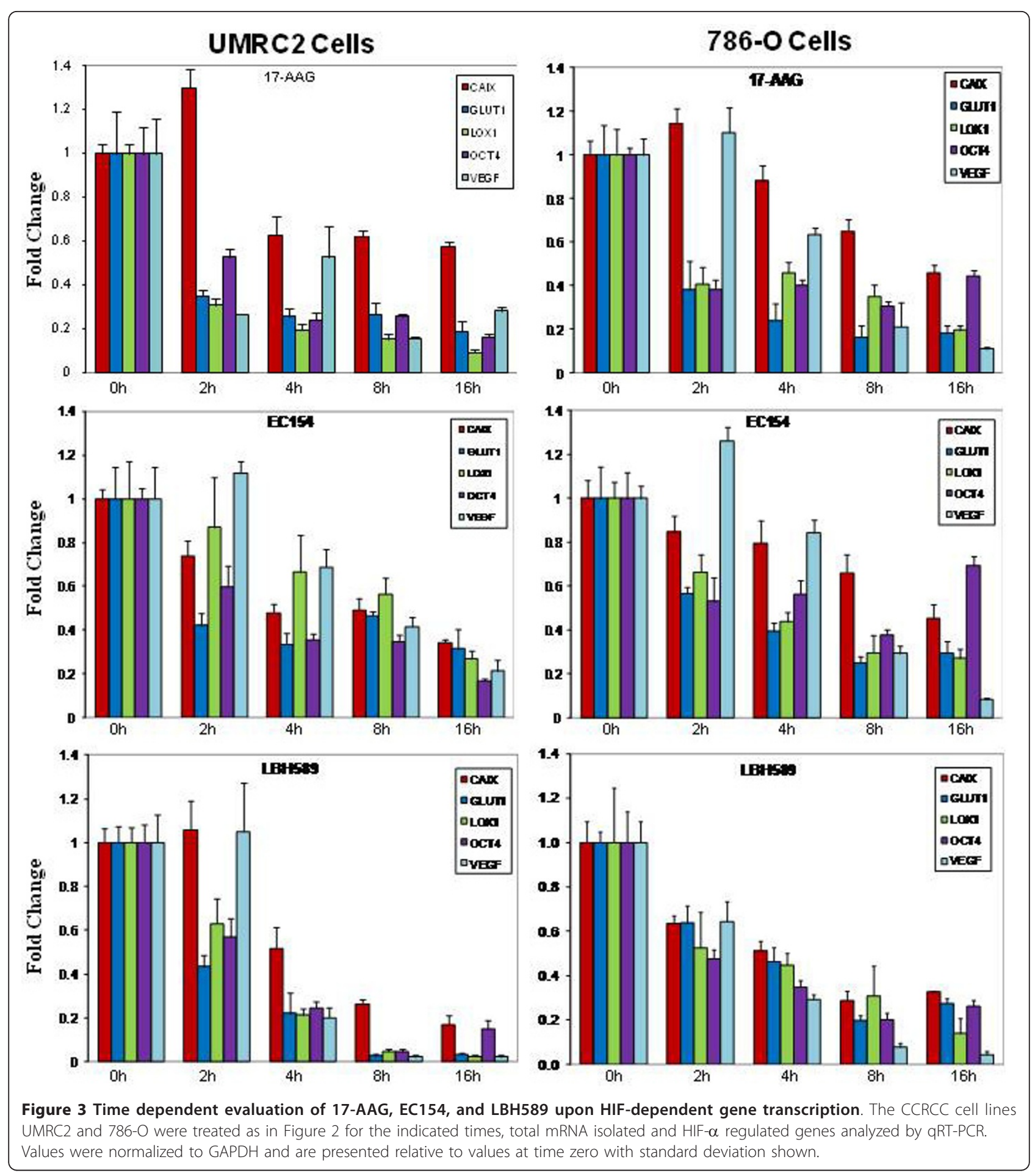

suppressed HIF-driven luciferase expression after $16 \mathrm{~h}$ in both cell types, with a greater extent of inhibition observed in UMRC2 (Figure 4a). However, within this model, LBH589 demonstrated comparable effects upon HIF dependent reporter expression in both cell lines, despite eliciting comparatively greater suppression in
UMRC2 as determined by qRT-PCR (Figures 2 and 3). Given the variations between HIF- $\alpha$ protein expression and HIF transcriptional activity, we next examined whether the expression of HIF-regulated proteins mirrored the trends of their transcript levels. The HIF signaling pathway regulates numerous pro-tumorigenic 


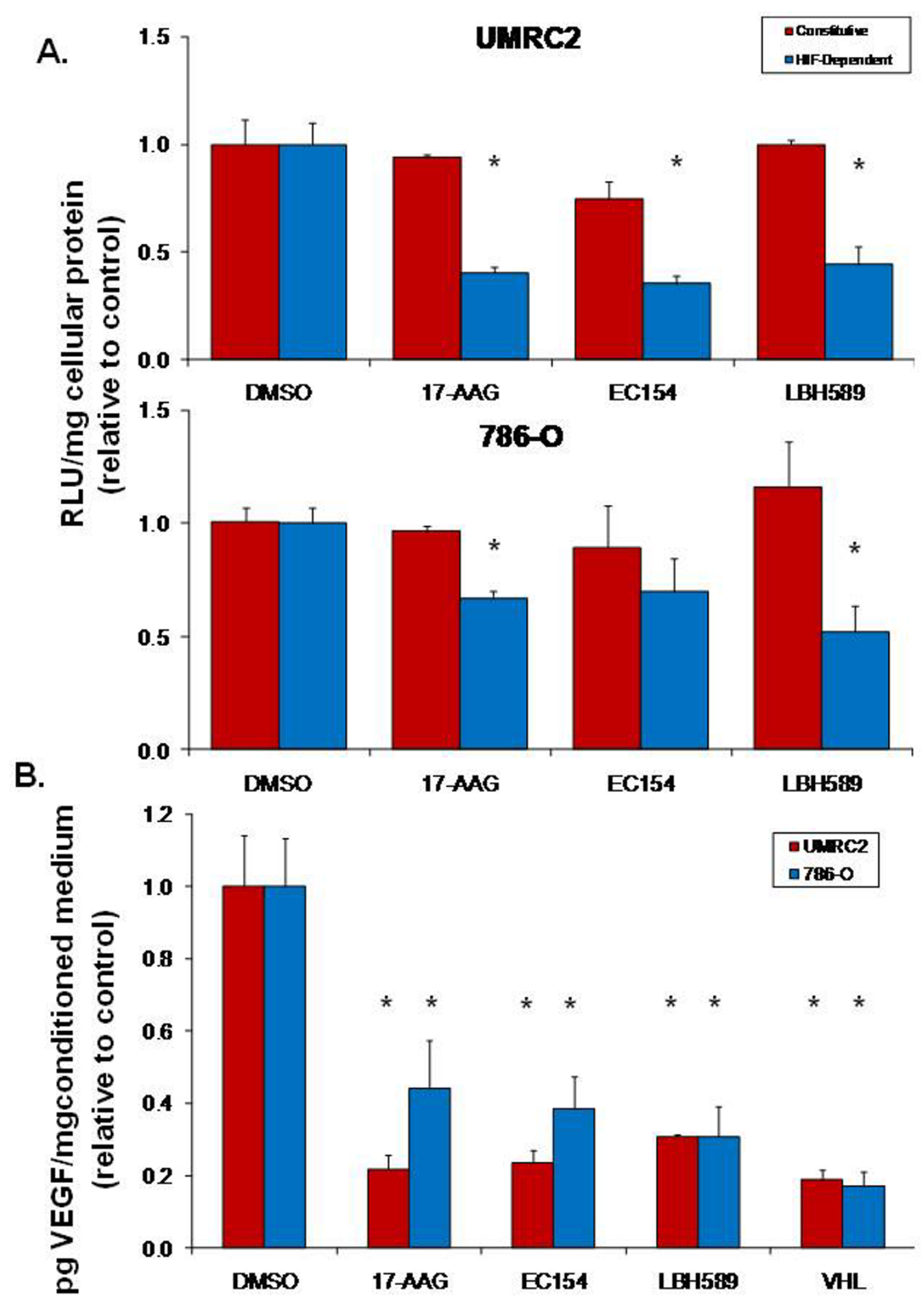

Figure 4 17-AAG, EC154, and LBH589 suppress HIF-dependent reporter gene expression and VEGF secretion. (a) CCRCC cells were transiently transfected with either a constitutive or VEGF HRE-driven luciferase reporter construct, treated for $16 \mathrm{~h}$ with inhibitors, and luciferase enzyme activity determined in whole cell lysates. All drug treatments significantly reduced HIF-dependent reporter gene expression $\left(^{*}\right)$ in both cell types with the exception of EC154 in 786-O, as determined by ANOVA and Student's $t$-test $(p<0.05)$. (b) CCRCC cells were pre-treated for 4 $\mathrm{h}$ with inhibitors in reduced serum DMEM (3\% FBS), and incubated for an additional $16 \mathrm{~h}$ with freshly prepared treatments in reduced serum medium. Conditioned medium was collected and VEGF levels were analyzed by ELISA. Values were normalized to total protein in conditioned medium and presented relative to controls, with standard deviation. All drug treatments significantly reduced VEGF secretion (*) in both cell types, as determined by ANOVA and Student's $t$-test $(p<0.05)$. 
pathways including angiogenesis and vasculogenesis $[2,64,65]$ and VEGF is a major contributor of HIF-driven angiogenesis. Hsp90 inhibitors such as 17-AAG decrease HIF-dependent production of CCRCC derived VEGF [66] and LBH589 has been shown to inhibit VEGF signaling in endothelial cells [67]. To further interrogate drug mediated effects upon HIF, we next evaluated the effects of these agents upon VEGF secretion. As shown in Figure 4b, all three drugs significantly reduced secreted VEGF levels in both cell types, congruous with the qRT-PCR results (Figure 3). Interestingly, 17-AAG and EC154 appeared somewhat less effective in reducing intracellular VEGF levels (Additional file 2: Figure S2). The significance of this is not entirely clear given that the secreted protein represents the biologically relevant fraction initiating HIF-mediated angiogenesis. However, this finding illustrates another level of complexity in that intracellular and secreted pools of HIF target proteins may be differentially susceptible to therapeutics.

\section{Dose dependent efficacy of inhibitors upon VEGF and uPA secretion}

In addition to VEGF, HIF activation promotes secretion of the pro-angiogenic urokinase plasminogen activator (uPA) $[68,69]$. In conjunction with its receptor uPAR, uPA regulates the plasminogen pathway to stimulate MMP activity and influence bioavailability of many HIF-regulated growth factors [70]. To examine the relative potency of these agents, we evaluated the dose dependent effects of these agents upon secreted VEGF and UPA in UMRC2 cells. Surprisingly, by this metric, EC154 and LBH589 were significantly more potent than 17-AAG (Figure 5), evidenced by their far more robust suppression of both VEGF and UPA $\left(\mathrm{IC}_{50}=0.006-0.28 \mu \mathrm{M}\right)$ as compared 17AAG (14.8-31.6 $\mu \mathrm{M})$. Interestingly, LBH589 demonstrated the strongest potency against uPA relative to the other agents $\left(\mathrm{IC}_{50}=0.006 \mu \mathrm{M}\right)$. Cell viability analysis by MTT assay supports that these drug dependent effects were due specifically to modulation of protein secretion and not a result of decreased cell proliferation (Additional file 3: Figure S3). We previously demonstrated that GA effectively reduced VEGF transcript expression and associated angiogenesis in RCC cells under hypoxic conditions [25]. To confirm that EC154 and LBH589 similarly maintain efficacy under hypoxia, UMCRC2 and 786-O cells were exposed to hypoxia $[25,71]$ for $16 \mathrm{~h}$ in either the presence or absence of these agents. As shown (Additional file 4: Figure S4), both EC154 and LBH589 potently suppressed uPA and VEGF secretion under hypoxia.

\section{Dose dependent effects of inhibitors upon CCRCC cell motility and associated molecular effectors}

The ability of these agents to elicit suppression of VEGF and UPA secretion at doses several log below their suggested optimal dose was intriguing. To explore whether low doses of these agents were able to suppress additional parameters of tumorigenicity, we evaluated their effects upon CCRCC cell motility, a property associated with HIF activity in CCRCC and other models [72-74], and additionally influenced by both VEGF and uPA. As shown in Figure 6a, 17-AAG and EC154 completely ablated UMRC2 cell motility at doses as low as $0.01 \mathrm{nM}$. In support of this finding, femtomolar levels of geldanamycin derivatives have been previously reported to inhibit invasion in human glioblastoma and myosarcoma cells through a proposed mechanism distinct from degradation of Hsp90 client proteins [75]. To further correlate our migration results with changes in relevant pro-motility signaling mediators, we examined the concentration dependent effects of these agents upon ERK, FAK, and src [76,77]. As shown in Figure 6b, only the high drug concentration of each agent suppressed ERK and FAK activation in UMRC2, the latter only observed with EC154. Src activation was not altered with either 17-AAG or EC154 and was only modestly reduced by the higher dose of LBH589. In contrast, ERK, FAK, and src phosphorylation were more susceptible to drug treatment in 786-O cells, wherein high concentrations of all three drugs reduced phosphorylation of these signaling mediators. Interestingly, low dose 17-AAG appeared to increase src phosphorylation, an effect most profoundly observed in 786-O cells, (10 pM 17-AAG), and not as readily observed with EC154. This 17-AAG mediated upregulation in src phosphorylation correlates with its reported ability to activate src activity in osteoclasts [78]. The drug mediated suppression of cell motility in UMRC2 independent from equivalent suppression of either FAK or src activity suggests that these agents impact upon alternative pro-motility factors. One likely candidate is uPA, given the ability of low drug concentrations to potently impair uPA secretion (Figure 5). Given that $\mathrm{UPA}$ regulates cell motility in part via integrin signaling [79], our findings suggest that these agents may impair motility in part via blockade of an uPAintegrin dependent pathway. Other possibilities include changes to the acetylation status of tubulin following inhibition of either Hsp90 or HDACs [80,81].

\section{Inhibitors potently suppress CCRCC mediated tubule formation but differentially modulate endothelial barrier function}

CCRCC tumors are among the most vascular, demonstrating the clinically important role of HIF in modulating levels of secretory factors that influence the tumor microenvironment. Given that low doses of these inhibitors elicited potent effects upon CCRCC motility, signaling, and secretion of UPA and VEGF, we examined the effects of these agents upon CCRCC mediated 

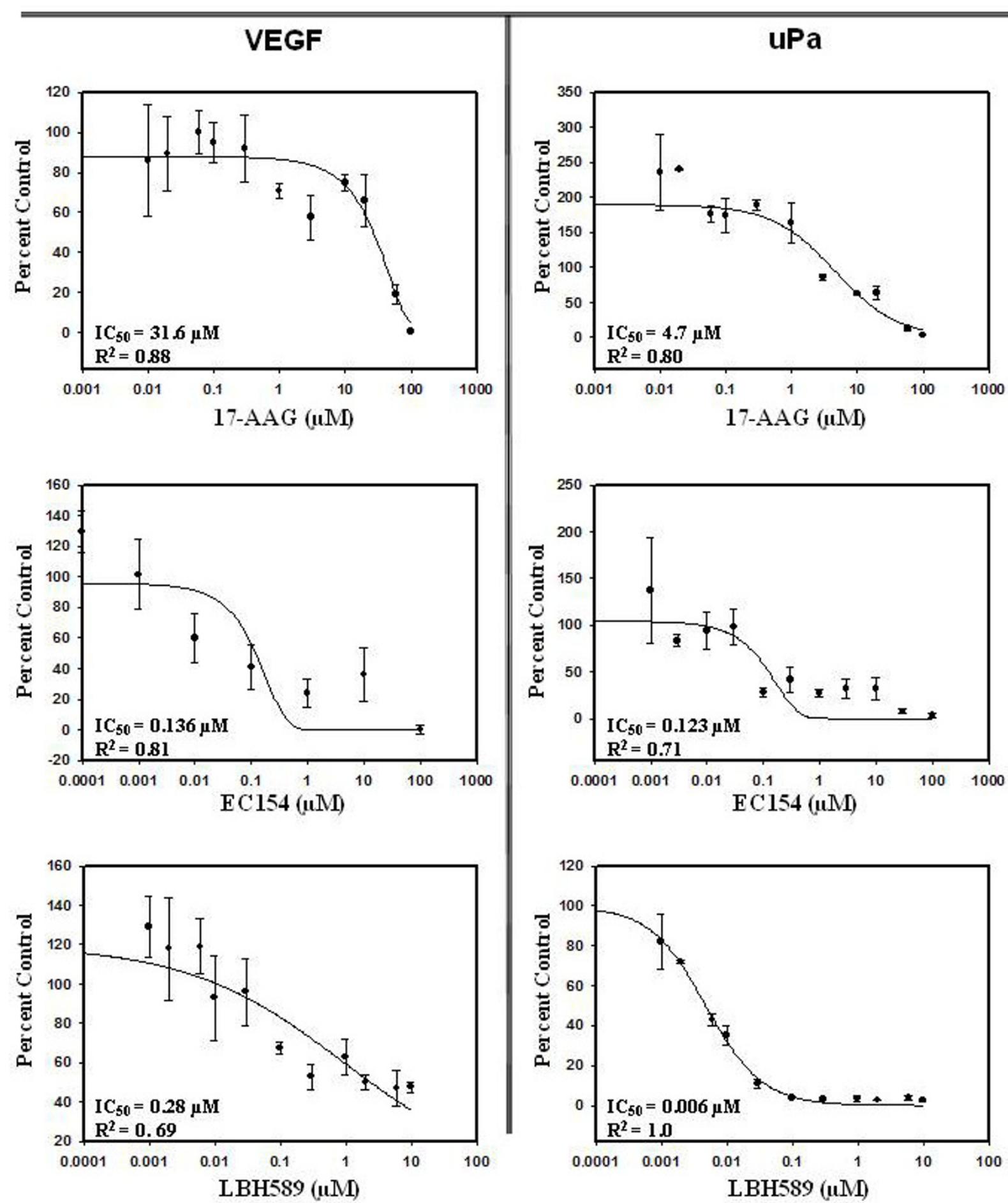

Figure 5 Ability of agents to suppress VEGF and uPA secretion in UMRC2 cells. UMRC2 cells were pre-treated for $4 \mathrm{~h}$ with the indicated doses of agents in reduced serum as in Figure 4. Conditioned medium was collected and both VEGF and UPA levels were analyzed by ELISA. Values were normalized to total protein in conditioned medium and are presented as percent of cytokine secretion relative to control with standard deviation. 


\section{A.}

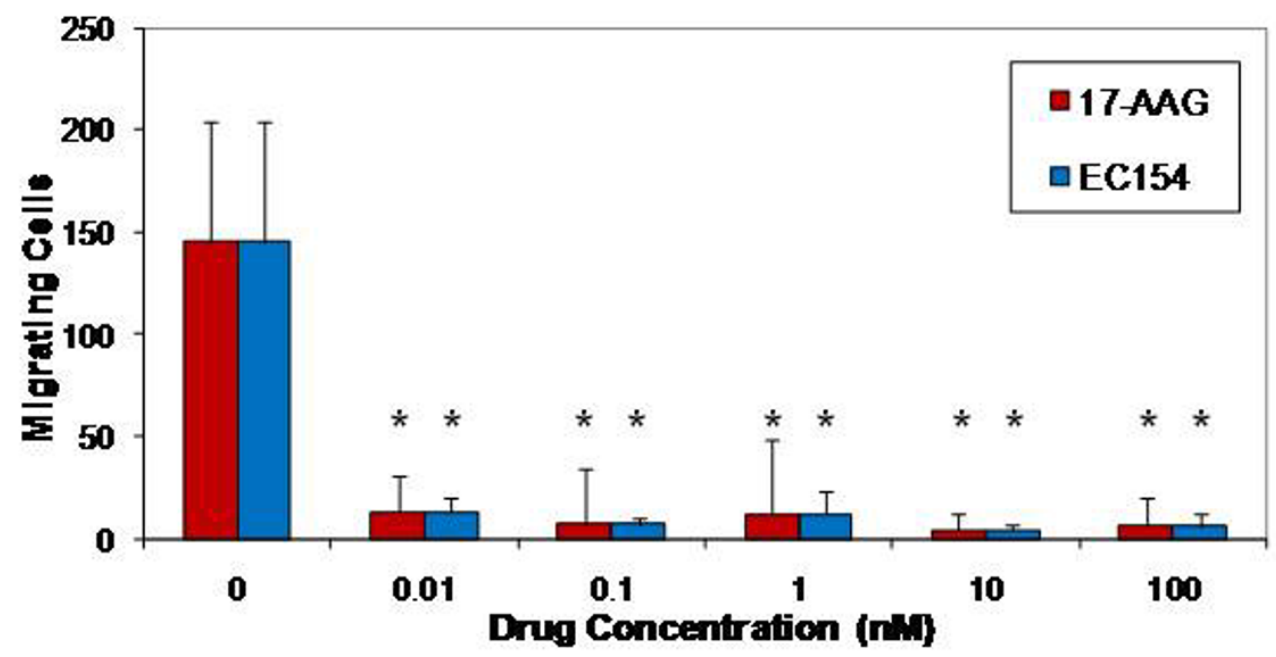

B.

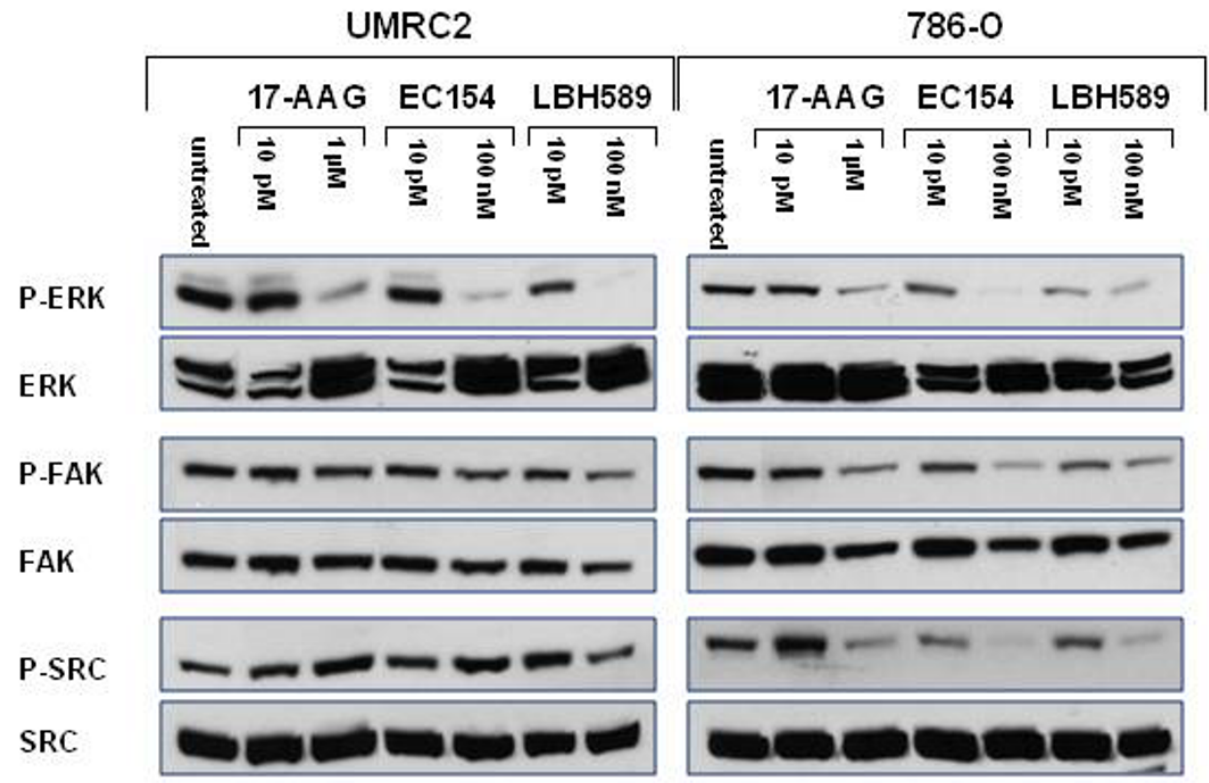

Figure 6 17-AAG and EC154 suppress UMRC2 cell motility and differentially modulate ERK, FAK, and src activation. (a) Serum starved UMRC2 cells were plated in transwell Boyden chambers for $16 \mathrm{~h}$ with a serum gradient of $0.1 \%$ (top) to $10 \%$ (bottom) in the presence of serially diluted concentrations of the indicated Hsp90 inhibitors. Migrating cells were fixed with $3.7 \%$ formaldehyde, stained with Crystal Violet and counted, with standard deviation shown. All drug treatments significantly inhibited migration in both cell types $(*)$, as determined by ANOVA and Student's t-test $(p<0.05)$. (b) UMRC2 and 786-O cells were treated for $20 \mathrm{~h}$ with the indicated doses of inhibitors and phosphorylated and total ERK, FAK, and src were analyzed by SDS-PAGE and Western blot. 
angiogenesis. Although previous reports have demonstrated the ability of these agents to inhibit tubule formation initiated by a single specific growth factor $[31,67]$, tumors promote angiogenesis via secretion of a complex mixture of growth factors. We therefore determined the relative ability of these agents to inhibit tubule formation when challenged by exposure to the physiologically relevant secreted milieu derived from CCRCC cells. As shown in Figure 7, conditioned medium derived from both UMRC2 and 786-O cells stimulated HUVEC tubule formation within $6 \mathrm{~h}$, an effect attenuated with the addition of each of the three drugs. Importantly, low dose treatment of all three drugs reduced tubule formation to levels comparable to the untreated control, and high dose treatment of the ATP Hsp90 inhibitors 17-AAG and EC154 further inhibited tubule formation to levels below untreated controls.

A complementary critical component of vessel function is permeability. Paracrine signals from the tumor promote the weakening of endothelial cell junctions. As a result of this diminished barrier function, the tumor vasculature becomes characteristically disordered, permeable, and leaky. This enhanced permeability promotes the ability of cancer cells to breach the vasculature in a process termed transendothelial migration (TEM) [82]. VEGF is among the best studied mediators of endothelial paracellular permeability [83]. Although CCRCC tumors are highly angiogenic, no reports have investigated the cumulative effects of CCRCC secreted factors upon endothelial barrier function, nor have any of the agents herein been evaluated for their capacity to counteract paracrine tumor factors that breach endothelial cell integrity. To examine endothelial barrier function upon challenge with CCRCC conditioned medium, and the ability of the inhibitors to counteract potential effects of this exposure, we utilized electric cell-substrate impedance sensing (ECIS). As shown in Figure 7b, conditioned medium from both UMRC2 and 786-O cells dramatically reduced endothelial cell barrier function. This effect was not replicated by conditioned medium from HUVECs, validating CCRCC derived specific effects. Moreover, the effect of CCRCC conditioned medium was greater than that of VEGF alone (Additional file 5: Figure S5) supporting the notion that tumor cells modulate endothelial cell integrity via a complex mixture of effectors. Importantly, both 17AAG and EC154 were able to restore barrier function in HUVECs challenged with CCRCC conditioned medium. Although 17-AAG has been previously demonstrated to restore barrier function upon exposure to a single cytokine $[84,85]$, this is the first study to highlight its ability to maintain endothelial cell integrity upon exposure to a complex mixture of tumor derived paracrine factors. Strikingly, a similar recovery effect was not observed with LBH589. That LBH589 did not restore endothelial barrier function in a similar manner is unexpected and suggests the possibility a non-Hsp90 mediated effect.

\section{Discussion}

Given the well established role of HIF in CCRCC, and its seemingly universal involvement in the progression of diverse solid tumors, it is critically important to evaluate the HIF targeting ability of next-generation Hsp90 inhibitors. However, surprisingly few studies have examined this particular aspect of these agents. The results from this study indicate that standard endpoints for HIF function may be less informative than previously indicated, and that the apparent complexity of inhibitor effects requires a more functionally based and integrative approach. One example of this complexity is demonstrated by our findings that although all three compounds significantly reduced HIF- $1 \alpha$ protein levels, consistent with previous reports [25-27,45], 17-AAG and EC154 did not appreciably diminish HIF-2 $\alpha$ levels, and surprisingly, LBH589 increased HIF- $2 \alpha$ expression. To our knowledge, this is the first report to examine the effect of an HDAC inhibitor on HIF-2 $\alpha$ levels, and more significantly, to demonstrate an HDAC dependent increase in protein expression. It remains unclear whether the mechanism of LBH589 mediated increase of HIF- $2 \alpha$ protein may be due to changes in protein degradation or synthesis. Further, the requirement of RACK1 for Hsp90-inhibition mediated HIF-2 $\alpha$ degradation has not been established. The differential response of the HIF isoforms is not without precedent, in that isoform specificity for HIF- $1 \alpha$ and HIF- $2 \alpha$ has been demonstrated during oxygen and VHL independent destruction pathways $[86,87]$. However, of greater relevance to this study is that the LBH-589 mediated increase in HIF- $2 \alpha$ expression did not elicit a comparable increase in HIF-2 $\alpha$ activity.

Our findings reinforce the theme that HIF expression and activity may be uncoupled events, a notion previously observed following treatment with proteasomal inhibitors [59]. First, although LBH589 increased HIF-2 expression, all other parameters of HIF activity support an overall suppressive effect. Given that HIF activity is regulated by acetylation, it is very possible that the increase in HIF acetylation by LBH-589 is inhibitory. Further, increased acetylation has also been shown to inhibit Hsp90 chaperone activity [44], which may further suppress HIF- 2 activity. Second, all three drugs diminished HIF- $1 \alpha$ and HIF- $2 \alpha$ dependent transcription within $2 \mathrm{~h}$ of treatment, prior to decreases in protein levels $[25,88]$, and data not shown. Although EC154 and 17-AAG demonstrated approximately equivalent kinetics of suppression, exposure of cells to low concentrations of EC154 (10-fold lower levels than the experimental 
A.

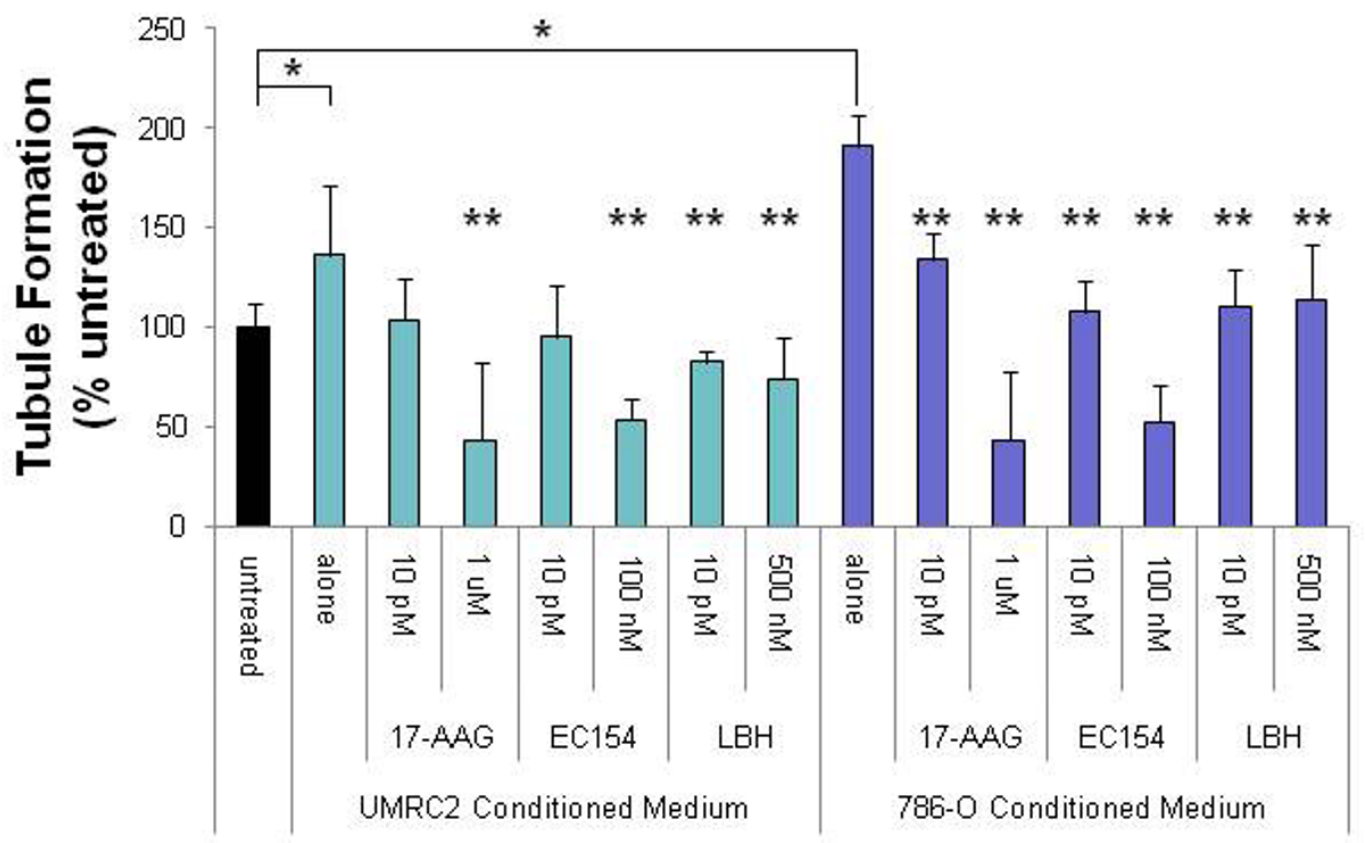

B.
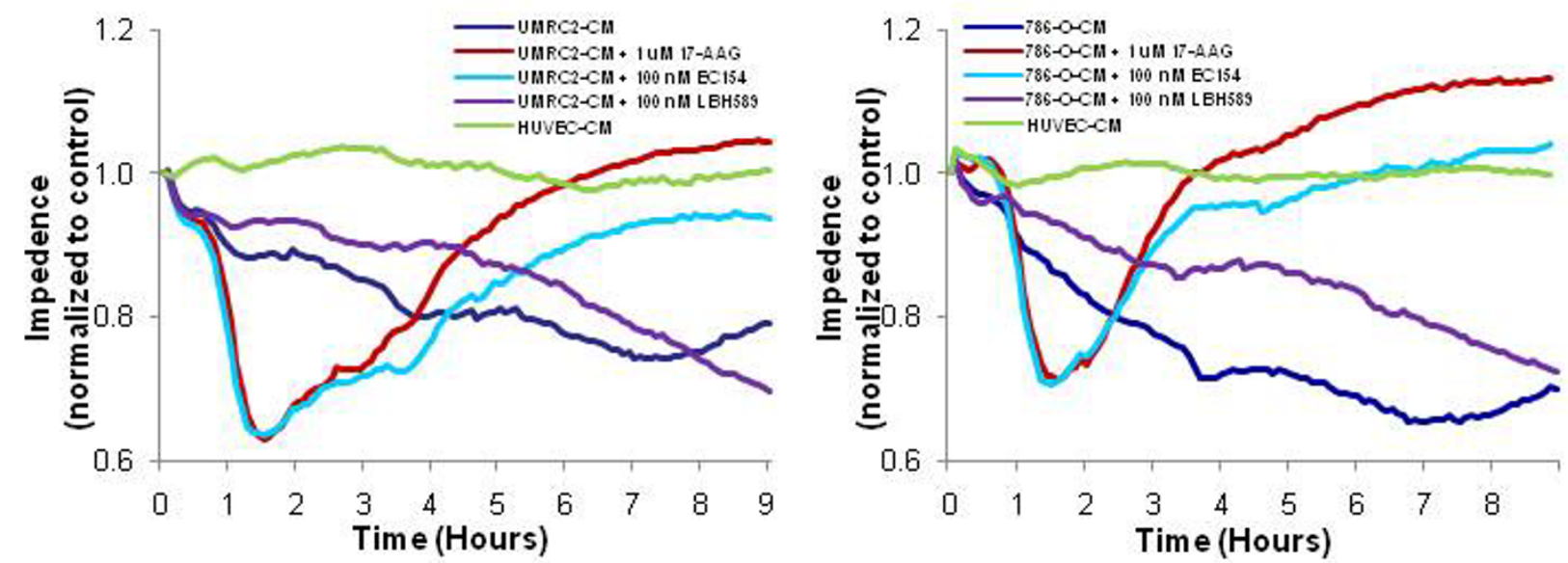

Figure 7 17-AAG, EC154, and LBH589 suppress CCRCC mediated tubule formation and differentially modulate endothelial barrier function. a) Serum starved (0.1\%) HUVEC cells were plated on growth factor reduced Matrigel in the presence of CCRCC conditioned medium (UMRC2 or 786-0) in the presence or absence of 17-AAG, EC154, or LBH589. Tubule formation was imaged at $6 \mathrm{~h}$ from 6 replicate wells of a 96well plate (1 field per well at $40 \times$ magnification), branch points counted, and presented as a percent of untreated control with standard deviation. Conditioned medium from both cell types significantly induced tubule formation $\left(^{*}\right)$ as determined by Student's $t$-test $(p<0.05)$. Drug treatments that significantly reversed the effects of conditioned medium are indicated $\left.{ }^{* *}\right)$ as determined by ANOVA and Student's $t$-test $(p<$ 0.05). b) Monolayers of HUVEC cells were allowed to reach a minimal TEER plateau and subsequently incubated with conditioned medium from UMCRC2 (left panel) or 786-O cells (right panel) in the presence or absence of 17-AAG, EC154, or LBH589. Conditioned medium from HUVEC cells was used as a negative control. Impedance was measured at $5 \mathrm{~min}$ intervals, normalized to levels just prior to the addition of effectors, and presented relative to untreated control. The traces shown represent an average of two replicates per condition. 
$100 \mathrm{nM}$ ) did not elicit detectable increases in src phosphorylation, indicating an improved profile compared with 17-AAG.

Our data highlight the complexity of drug targeting, in that the drug mediated suppression of HIF target genes varied dynamically with time and dose, and differential sensitivity was observed in a transcript and cell context dependent manner. This complexity is not surprising given that additional modifiers may contribute to the net effects of Hsp90 inhibition. For example, NF-kB promotes HIF- $1 \alpha$ transactivation in an acetylation sensitive manner [89] and coordinates suppressive effects upon NF-kB, and Hsp90 may contribute to the robust inhibition of HIF activity observed with LBH589. Moreover, HDAC inhibition at early time points has also been demonstrated to disrupt the p300:HIF complex, a critical component of HIF transactivation, resulting in decreased HIF transcriptional activity [88]. Adding to this complexity, HIF directly interacts with, and is regulated by, HDACs [90] illustrating several nodal points by which Hsp90 and HDAC inhibitors may distinctly impact upon HIF function.

To more comprehensively evaluate the relative efficacy of these agents against specific metrics, we examined key anticancer properties beyond HIF transcription. Sub-nanomolar concentrations of 17-AAG and EC154 profoundly suppressed CCRCC cell motility, whereas higher concentrations were required to diminish CCRCC-mediated HUVEC tubule formation. Although LBH589 demonstrated the most potent suppression of both VEGF transcription and secreted protein, it only modestly prevented tubule formation in 786-O. Our tubule formation results support the notion that Hsp90 inhibiting agents, in part via their suppressive effects upon HIF, may be utilized clinically to reduce the vascularity associated with CCRCC and other solid tumors [31,67]. Although LBH589 did not restore barrier function, another report demonstrates that this agent, in combination with rapamycin in a preclinical model, was effective in reducing CCRCC angiogenesis [15]. A recent report found that pre-incubation with the HDAC6 inhibitor tubacin prevents thrombin induced barrier damage [91], suggesting that the effects of HDAC inhibition upon vessel permeability could vary greatly depending upon a variety of factors. Therefore, the ECIS assay may be a useful approach to more fully interrogate the ability of LBH589, and other HDACIs, to restore endothelial cell function alone and in combination with currently utilized anticancer agents. The ability of these agents to preserve endothelial cell integrity could have significant effects on clinical outcome and warrants further attention. Clinically, vascular permeability can promote tumor cell TEM and metastasis [82] and poses a further challenge in diminishing the delivery and efficacy of chemo- and radio-therapies [92]. Our results suggest that these agents may have utility in 'normalizing' the tumor vasculature, an effect that improves chemo- and radio-therapy [92]. Although not formally demonstrated for Hsp90 inhibitors, 17-AAG and radicicol have been shown to improve endothelial barrier formation and rescue barrier in the presence of damaging agents including thrombin, VEGF, and phorbal ester [84,85]. In addition, we previously demonstrated that both GA and 17-AAG potentiate the radiation response of cervical tumor cells in vitro and in vivo [29]. Our data suggest that EC154 exhibits a similar capacity as 17-AAG in terms of its ability to restore barrier function, and may therefore represent a viable clinical candidate.

\section{Conclusions}

In sum, our transcriptional results indicate that Hsp90 inhibition may affect HIF-dependent gene transcription through at least two mechanisms; by direct inhibition of transcriptional activity at early time points, and by promotion of HIF- $1 \alpha$ degradation at later time points. This further highlights the complexity of Hsp90 inhibitor effects and weakens the notion that variations of HIF- $\alpha$ isoform stability is a primary reason for the clinical failure of these agents [34]. Importantly, our results also highlight that HIF expression is not necessarily a reliable surrogate for interrogating the HIF targeting efficacy of Hsp90 inhibitors. This is a particularly salient finding in light of recent efforts to improve in vivo and intratumoral imaging of Hsp90 client proteins as a surrogate for monitoring inhibitor activity [93-97]. Moreover, our results further indicate that levels of HIF regulated cytokines such as VEGF may also be unreliable surrogates for HIF activity, demonstrated by the observed differential effects of Hsp90 inhibition upon intracellular and secreted VEGF. This finding further highlights the challenge in choosing appropriate biomarkers, in that the histochemical analysis of tumor tissues for VEGF expression would indicate less robust drug dependent effects compared with an analysis of secreted levels of the same protein. Our findings highlight the need to integrate multiple, diverse, and functional endpoints to more appropriately discern the effects of Hsp90 inhibition upon HIF function. With more than a dozen new Hsp90 inhibitors currently under clinical evaluation [98], there is a critical need to establish relevant and reliable surrogates and biomarkers for evidence of Hsp90 inhibition. The identification of these readouts and their subsequent incorporation into clinical trials will provide useful indicators of positive response. Our findings offer useful metrics and considerations to guide the preclinical and clinical evaluation of conventional and novel Hsp90 inhibitors. 


\section{Additional material}

Additional file 1: Figure S1. Dose dependent effects of 17-AAG, EC154, and LBH589 upon HIF-dependent gene transcription in 786-O. 786-O cells were treated for $16 \mathrm{~h}$ with the indicated concentrations of inhibitors, total mRNA was isolated and HIF- $\alpha$ regulated genes analyzed by QRT-PCR. Values were normalized to GAPDH and are presented relative to control, with standard deviation. Stably transfected VHL replaced cells were used as a control condition for HIF suppression.

Additional file 2: Figure S2. Effects of 17-AAG, EC154, and LBH589 upon intracellular VEGF expression in CCRCC cells. CCRCC cells (786-O and UMRC2) were pre-treated for $4 \mathrm{~h}(1 \mathrm{\mu M}$ 17-AAG, $100 \mathrm{nM}$ EC154, 100 nM LBH589) in reduced serum DMEM (3\% FBS). Cells were then reincubated for an additional $16 \mathrm{~h}$ with freshly prepared treatments in reduced serum medium. Whole cell lysate was collected and VEGF levels were determined by ELISA. Values are normalized to total cellular protein and presented as a percent of DMSO treated control with standard deviation. All drug treatments significantly reduced HIF-dependent reporter gene expression $\left(^{*}\right)$ in both cell types with the exception of EC154 in 786-O, as determined by ANOVA and Student's $t$-test $(p<0.05)$.

Additional file 3: Figure S3. Administration of 17-AAG, EC154, and LBH589 does not affect CCRCC viability within $16 \mathrm{~h}$. CCRCC cells were incubated for $16 \mathrm{~h}$ with vehicle or the indicated agents and cell viability was determined by MTT assay, with data presented as a percent of control cells, with standard deviation

Additional file 4: Figure S4. Suppression of VEGF and UPa secretion by EC154 and LBH589 in CCRCC cells under hypoxia. CCRCC cells were pretreated for $4 \mathrm{~h}$ with inhibitors in reduced serum DMEM (3\% FBS), and incubated for an additional $16 \mathrm{~h}$ with freshly prepared treatments in reduced serum medium at $1 \% \mathrm{O}_{2}$. Conditioned medium was collected and VEGF and UPa levels were analyzed by ELISA. Values were normalized to total protein in conditioned medium and presented relative to controls, with standard deviation.

Additional file 5: Figure S5. VEGF elicits a modest breach of endothelial integrity, which is rescued by 17-AAG. Monolayers of HUVEC cells were allowed to reach a minimal TEER plateau and then incubated with VEGF $(50 \mathrm{ng} / \mathrm{mL})$ in the presence or absence of 17-AAG $(1 \mu \mathrm{M})$. Impedance was measured at 5 min intervals, normalized to levels just prior to the addition of effectors, and presented relative to untreated control. The traces shown represent an average of two replicates per condition.

\section{Acknowledgements}

This work was supported by NIH grant numbers K22 CA107212-01 (J.S.I), K12GM081265 (Program Director, C.F. Wright), P20 RR016461 from the National Center for Research Resources, HL80404 (K.M.A.), RR107677 (K.M.A.), and a commercial grant from Biogen-IDEC. We acknowledge Yefim Mannovich for his assistance with Sigma Plot calculations and Peter Atajda for generously supplying us with LBH589.

\section{Author details}

'Department of Cell and Molecular Pharmacology, Medical University of South Carolina, Charleston, SC, USA. ${ }^{2}$ Cancer Research Institute, Central South University, Changsha, China. ${ }^{3}$ Department of Regenerative Medicine and Cell Biology, Medical University of South Carolina, Charleston, SC, USA. ${ }^{4}$ Biogen Idec, San Diego, CA, USA.

\section{Authors' contributions}

JEB participated in the design of the study, performed immunoblots, immunoassays, cell migration, tubule formation, cell viability and ECIS experiments, statistical analysis, and drafted the manuscript. SP carried out the GRT-PCR studies, lentiviral infections, and reporter assays. UG carried out studies pertinent to the activity status of pro-motility effector proteins. MWH participated in the cell migration studies. SW and KA participated in the design, execution, and analysis of the ECIS experiments. KL participated in the design and coordination for the study and provided EC154. JSI conceived of the study, participated in its design and coordination, and edited the manuscript. All authors read and approved the final manuscript.

\section{Competing interests}

This work was funded in part by a commercial grant from Biogen Idec.

Received: 24 June 2011 Accepted: 15 December 2011

Published: 15 December 2011

\section{References}

1. Semenza GL: Targeting HIF-1 for cancer therapy. Nat Rev Cancer 2003, 3:721-732

2. Semenza GL: Defining the role of hypoxia-inducible factor 1 in cancer biology and therapeutics. Oncogene 2009.

3. Wang $G L$, Jiang BH, Rue EA, Semenza GL: Hypoxia-inducible factor 1 is a basic-helix-loop-helix-PAS heterodimer regulated by cellular $\mathrm{O} 2$ tension. Proc Natl Acad Sci USA 1995, 92:5510-5514.

4. Qing G, Simon MC: Hypoxia inducible factor-2alpha: a critical mediator of aggressive tumor phenotypes. Curr Opin Genet Dev 2009, 19:60-66.

5. Mabjeesh NJ, Amir S: Hypoxia-inducible factor (HIF) in human tumorigenesis. Histol Histopathol 2007, 22:559-572.

6. Semenza GL: Involvement of hypoxia-inducible factor 1 in human cancer. Intern Med 2002, 41:79-83.

7. Burkitt K, Chun SY, Dang DT, Dang LH: Targeting both HIF-1 and HIF-2 in human colon cancer cells improves tumor response to sunitinib treatment. Mol Cancer Ther 2009, 8:1148-1156.

8. Kaelin WG Jr: The von Hippel-Lindau tumor suppressor protein and clear cell renal carcinoma. Clin Cancer Res 2007, 13:680s-684s.

9. Maranchie JK, Vasselli JR, Riss J, Bonifacino JS, Linehan WM, Klausner RD: The contribution of VHL substrate binding and HIF1-alpha to the phenotype of VHL loss in renal cell carcinoma. Cancer Cell 2002, 1:247-255

10. Kondo K, Kim WY, Lechpammer M, Kaelin WG Jr: Inhibition of HIF2alpha is sufficient to suppress PVHL-defective tumor growth. PLOS Biol 2003, 1 E83.

11. Kondo K, Klco J, Nakamura E, Lechpammer M, Kaelin WG Jr: Inhibition of HIF is necessary for tumor suppression by the von Hippel-Lindau protein. Cancer Cell 2002, 1:237-246.

12. Niopoulos O, Levy AP, Jiang C, Kaelin WG Jr, Goldberg MA: Negative regulation of hypoxia-inducible genes by the von Hippel-Lindau protein. Proc Natl Acad Sci USA 1996, 93:10595-10599.

13. Mandriota SJ, Turner KJ, Davies DR, Murray PG, Morgan NV, Sowter HM, Wykoff CC, Maher ER, Harris AL, Ratcliffe PJ, Maxwell PH: HIF activation identifies early lesions in VHL kidneys: evidence for site-specific tumor suppressor function in the nephron. Cancer Cell 2002, 1:459-468.

14. Biswas S, Troy H, Leek R, Chung YL, Li JL, Raval RR, Turley H, Gatter K, Pezzella F, Griffiths JR, et al: Effects of HIF-1alpha and HIF2alpha on Growth and Metabolism of Clear-Cell Renal Cell Carcinoma 786-0 Xenografts. J Oncol 2010, 2010:757908.

15. Verheul HM, Salumbides B, Van Erp K, Hammers H, Qian DZ, Sanni T, Atadja P, Pili R: Combination strategy targeting the hypoxia inducible factor-1 alpha with mammalian target of rapamycin and histone deacetylase inhibitors. Clin Cancer Res 2008, 14:3589-3597.

16. Carroll VA, Ashcroft M: Role of hypoxia-inducible factor (HIF)-1alpha versus HIF-2alpha in the regulation of HIF target genes in response to hypoxia, insulin-like growth factor-I, or loss of von Hippel-Lindau function: implications for targeting the HIF pathway. Cancer Res 2006, 66:6264-6270.

17. Toschi A, Lee E, Gadir N, Ohh M, Foster DA: Differential dependence of hypoxia-inducible factors 1 \{alpha\} and 2 \{alpha\} on mTORC 1 and mTORC2. J Biol Chem 2008, 283:34495-34499.

18. Rapisarda A, Uranchimeg B, Sordet O, Pommier Y, Shoemaker RH, Melillo G: Topoisomerase I-mediated inhibition of hypoxia-inducible factor 1: mechanism and therapeutic implications. Cancer Res 2004, 64:1475-1482

19. Koh MY, Spivak-Kroizman T, Venturini S, Welsh S, Williams RR, Kirkpatrick DL, Powis G: Molecular mechanisms for the activity of PX-478, an antitumor inhibitor of the hypoxia-inducible factor-1alpha. Mol Cancer Ther 2008, 7:90-100.

20. Semenza GL: Development of novel therapeutic strategies that target HIF-1. Expert Opin Ther Targets 2006, 10:267-280.

21. Zhang H, Qian DZ, Tan YS, Lee K, Gao P, Ren YR, Rey S, Hammers H, Chang D, Pili R, et al: Digoxin and other cardiac glycosides inhibit HIF1 alpha synthesis and block tumor growth. Proc Natl Acad Sci USA 2008, 105:19579-19586. 
22. Greenberger LM, Horak ID, Filpula D, Sapra P, Westergaard M, Frydenlund HF, Albaek C, Schroder $\mathrm{H}$, Orum H: A RNA antagonist of hypoxia-inducible factor-1alpha, EZN-2968, inhibits tumor cell growth. Mol Cancer Ther 2008, 7:3598-3608.

23. Kung AL, Zabludoff SD, France DS, Freedman SJ, Tanner EA, Vieira A, Cornell-Kennon S, Lee J, Wang B, Wang J, et al: Small molecule blockade of transcriptional coactivation of the hypoxia-inducible factor pathway. Cancer Cell 2004, 6:33-43.

24. Minet E, Mottet D, Michel G, Roland I, Raes M, Remacle J, Michiels C: Hypoxia-induced activation of HIF-1: role of HIF-1alpha-Hsp90 interaction. FEBS Lett 1999, 460:251-256.

25. Isaacs JS, Jung YJ, Mimnaugh EG, Martinez A, Cuttitta F, Neckers LM: Hsp90 regulates a von Hippel Lindau-independent hypoxia-inducible factor-1 alpha-degradative pathway. J Biol Chem 2002, 277:29936-29944.

26. Mabjeesh NJ, Post DE, Willard MT, Kaur B, Van Meir EG, Simons JW, Zhong H: Geldanamycin induces degradation of hypoxia-inducible factor 1 alpha protein via the proteosome pathway in prostate cancer cells. Cancer Res 2002, 62:2478-2482.

27. Katschinski DM, Le L, Schindler SG, Thomas T, Voss AK, Wenger RH: Interaction of the PAS B domain with HSP90 accelerates hypoxiainducible factor-1alpha stabilization. Cell Physiol Biochem 2004, 14:351-360.

28. Liu W, Baek JH, Zhang H, Diez R, Cole RN, Semenza GL: RACK1 competes with HSP90 for binding to HIF-1alpha and is required for $\mathrm{O}(2)$ independent and HSP90 inhibitor-induced degradation of HIF-1alpha. Mol Cell 2007, 25:207-217.

29. Bisht KS, Bradbury CM, Mattson D, Kaushal A, Sowers A, Markovina S, Ortiz KL, Sieck LK, Isaacs JS, Brechbiel MW, et al: Geldanamycin and 17allylamino-17-demethoxygeldanamycin potentiate the in vitro and in vivo radiation response of cervical tumor cells via the heat shock protein 90-mediated intracellular signaling and cytotoxicity. Cancer Res 2003, 63:8984-8995.

30. Hollingshead M, Alley M, Burger AM, Borgel S, Pacula-Cox C, Fiebig HH, Sausville EA: In vivo antitumor efficacy of 17-DMAG (17dimethylaminoethylamino-17-demethoxygeldanamycin hydrochloride), a water-soluble geldanamycin derivative. Cancer Chemother Pharmacol 2005, 56:115-125.

31. Sanderson S, Valenti M, Gowan S, Patterson L, Ahmad Z, Workman P, Eccles SA: Benzoquinone ansamycin heat shock protein 90 inhibitors modulate multiple functions required for tumor angiogenesis. $\mathrm{Mol}$ Cancer Ther 2006, 5:522-532.

32. Alqawi $O$, Moghaddas M, Singh G: Effects of geldanamycin on HIF-1alpha mediated angiogenesis and invasion in prostate cancer cells. Prostate Cancer Prostatic Dis 2006, 9:126-135.

33. Lang SA, Moser C, Gaumann A, Klein D, Glockzin G, Popp FC, Dahlke MH, Piso P, Schlitt HJ, Geissler EK, Stoeltzing O: Targeting heat shock protein 90 in pancreatic cancer impairs insulin-like growth factor-I receptor signaling, disrupts an interleukin-6/signal-transducer and activator of transcription 3/hypoxia-inducible factor-1alpha autocrine loop, and reduces orthotopic tumor growth. Clin Cancer Res 2007, 13:6459-6468.

34. Ronnen EA, Kondagunta GV, Ishill N, Sweeney SM, Deluca JK, Schwartz L, Bacik J, Motzer RJ: A phase II trial of 17-(Allylamino)-17demethoxygeldanamycin in patients with papillary and clear cell renal cell carcinoma. Invest New Drugs 2006, 24:543-546.

35. Kummar S, Gutierrez ME, Gardner ER, Chen X, Figg WD, Zajac-Kaye M, Chen M, Steinberg SM, Muir CA, Yancey MA, et al: Phase I trial of 17dimethylaminoethylamino-17-demethoxygeldanamycin (17-DMAG), a heat shock protein inhibitor, administered twice weekly in patients with advanced malignancies. Eur J Cancer 2010, 46:340-347.

36. Heath El, Hillman DW, Vaishampayan U, Sheng S, Sarkar F, Harper F, Gaskins M, Pitot HC, Tan W, Ivy SP, et al: A phase II trial of 17-allylamino17-demethoxygeldanamycin in patients with hormone-refractory metastatic prostate cancer. Clin Cancer Res 2008, 14:7940-7946.

37. Huang KH, Veal JM, Fadden RP, Rice JW, Eaves J, Strachan JP, Barabasz AF, Foley BE, Barta TE, Ma W, et al: Discovery of novel 2-aminobenzamide inhibitors of heat shock protein 90 as potent, selective and orally active antitumor agents. J Med Chem 2009, 52:4288-4305.

38. Okawa $Y$, Hideshima $T$, Steed $P$, Vallet $S$, Hall $S$, Huang $K$, Rice J, Barabasz A, Foley B, Ikeda H, et al: SNX-2112, a selective Hsp90 inhibitor, potently inhibits tumor cell growth, angiogenesis, and osteoclastogenesis in multiple myeloma and other hematologic tumors by abrogating signaling via Akt and ERK. Blood 2009, 113:846-855.
39. Breinig M, Caldas-Lopes E, Goeppert B, Malz M, Rieker R, Bergmann F, Schirmacher P, Mayer M, Chiosis G, Kern MA: Targeting heat shock protein 90 with non-quinone inhibitors: a novel chemotherapeutic approach in human hepatocellular carcinoma. Hepatology 2009, 50:102-112.

40. Chiosis G, Lucas B, Huezo H, Solit D, Basso A, Rosen N: Development of purine-scaffold small molecule inhibitors of Hsp90. Curr Cancer Drug Targets 2003, 3:371-376.

41. Taldone T, Gozman A, Maharaj R, Chiosis G: Targeting Hsp90: smallmolecule inhibitors and their clinical development. Curr Opin Pharmacol 2008, 8:370-374

42. Bali P, Pranpat M, Bradner J, Balasis M, Fiskus W, Guo F, Rocha K, Kumaraswamy S, Boyapalle S, Atadja P, et al: Inhibition of histone deacetylase 6 acetylates and disrupts the chaperone function of heat shock protein 90: a novel basis for antileukemia activity of histone deacetylase inhibitors. J Biol Chem 2005, 280:26729-26734.

43. Kovacs JJ, Murphy PJ, Gaillard S, Zhao X, Wu JT, Nicchitta CV, Yoshida M, Toft DO, Pratt WB, Yao TP: HDAC6 regulates Hsp90 acetylation and chaperone-dependent activation of glucocorticoid receptor. Mol Cell 2005, 18:601-607.

44. Scroggins BT, Robzyk K, Wang D, Marcu MG, Tsutsumi S, Beebe K, Cotter RJ, Felts S, Toft D, Karnitz $L$, et al: An acetylation site in the middle domain of hsp90 regulates chaperone function. Mol Cell 2007, 25:151-159.

45. Mie Lee Y, Kim SH, Kim HS, Jin Son M, Nakajima H, Jeong Kwon H, Kim KW: Inhibition of hypoxia-induced angiogenesis by FK228, a specific histone deacetylase inhibitor, via suppression of HIF-1alpha activity. Biochem Biophys Res Commun 2003, 300:241-246.

46. Kekatpure VD, Dannenberg AJ, Subbaramaiah K: HDAC6 modulates HSP90 chaperone activity and regulates activation of aryl hydrocarbon receptor signaling. J Biol Chem 2009.

47. Fiskus W, Ren Y, Mohapatra A, Bali P, Mandawat A, Rao R, Herger B, Yang Y, Atadja P, Wu J, Bhalla K: Hydroxamic acid analogue histone deacetylase inhibitors attenuate estrogen receptor-alpha levels and transcriptional activity: a result of hyperacetylation and inhibition of chaperone function of heat shock protein 90. Clin Cancer Res 2007, 13:4882-4890.

48. Qian DZ, Kachhap SK, Collis SJ, Verheul HM, Carducci MA, Atadja P, Pili R: Class II histone deacetylases are associated with VHL-independent regulation of hypoxia-inducible factor 1 alpha. Cancer Res 2006, 66:8814-8821.

49. Liang D, Kong $X$, Sang N: Effects of histone deacetylase inhibitors on HIF1. Cell Cycle 2006, 5:2430-2435.

50. Kong X, Lin Z, Liang D, Fath D, Sang N, Caro J: Histone deacetylase inhibitors induce VHL and ubiquitin-independent proteasomal degradation of hypoxia-inducible factor 1alpha. Mol Cell Biol 2006, 26:2019-2028.

51. Lundgren $\mathrm{K}$, Zhang $\mathrm{H}$, Brekken J, Huser N, Powell RE, Timple N, Busch DJ, Neely L, Sensintaffar JL, Yang YC, et al: BIIB021, an orally available, fully synthetic small-molecule inhibitor of the heat shock protein $\mathrm{Hsp} 90$. Mol Cancer Ther 2009, 8:921-929.

52. Yun TJ, Harning EK, Giza K, Rabah D, Li P, Arndt JW, Luchetti D, Biamonte MA, Shi J, Lundgren K, et al: EC144, a synthetic inhibitor of heat shock protein 90 , blocks innate and adaptive immune responses in models of inflammation and autoimmunity. J Immunol 2011, 186:563-575.

53. Tiruppathi C, Malik AB, Del Vecchio PJ, Keese CR, Giaever I: Electrical method for detection of endothelial cell shape change in real time: assessment of endothelial barrier function. Proc Natl Acad Sci USA 1992, 89:7919-7923.

54. Sowter HM, Raval RR, Moore JW, Ratcliffe PJ, Harris AL: Predominant role of hypoxia-inducible transcription factor (Hif)-1alpha versus Hif-2alpha in regulation of the transcriptional response to hypoxia. Cancer Res 2003, 63:6130-6134.

55. Maxwell PH, Wiesener MS, Chang GW, Clifford SC, Vaux EC, Cockman ME, Wykoff CC, Pugh CW, Maher ER, Ratcliffe PJ: The tumour suppressor protein VHL targets hypoxia-inducible factors for oxygen-dependent proteolysis. Nature 1999, 399:271-275.

56. Anelli V, Gault CR, Cheng AB, Obeid LM: Sphingosine kinase 1 is upregulated during hypoxia in U87MG glioma cells. Role of hypoxiainducible factors 1 and 2. J Biol Chem 2008, 283:3365-3375.

57. Menrad H, Werno C, Schmid T, Copanaki E, Deller T, Dehne N, Brune B: Roles of hypoxia-inducible factor-1alpha (HIF-1alpha) versus HIF-2alpha in the survival of hepatocellular tumor spheroids. Hepatology 2010, 51:2183-2192. 
58. Bohensky J, Terkhorn SP, Freeman TA, Adams CS, Garcia JA, Shapiro IM, Srinivas $\mathrm{V}$ : Regulation of autophagy in human and murine cartilage: hypoxia-inducible factor 2 suppresses chondrocyte autophagy. Arthritis Rheum 2009, 60:1406-1415.

59. Kaluz S, Kaluzova M, Liao SY, Lerman M, Stanbridge EJ: Transcriptional control of the tumor- and hypoxia-marker carbonic anhydrase 9: A one transcription factor (HIF-1) show? Biochim Biophys Acta 2009, 1795:162-172

60. Erler JT, Bennewith KL, Nicolau M, Dornhofer N, Kong C, Le QT, Chi JT, Jeffrey SS, Giaccia AJ: Lysyl oxidase is essential for hypoxia-induced metastasis. Nature 2006, 440:1222-1226

61. Mizukami Y, Kohgo Y, Chung DC: Hypoxia inducible factor-1 independent pathways in tumor angiogenesis. Clin Cancer Res 2007, 13:5670-5674.

62. Robey IF, Stephen RM, Brown KS, Baggett BK, Gatenby RA, Gillies RJ: Regulation of the Warburg effect in early-passage breast cancer cells. Neoplasia 2008, 10:745-756.

63. Zhang X, Gaspard JP, Chung DC: Regulation of vascular endothelial growth factor by the Wnt and K-ras pathways in colonic neoplasia. Cancer Res 2001, 61:6050-6054.

64. Semenza GL: HIF-1: using two hands to flip the angiogenic switch. Cancer Metastasis Rev 2000, 19:59-65.

65. Bohonowych JE, Gopal U, Isaacs JS: Hsp90 as a gatekeeper of tumor angiogenesis: clinical promise and potential pitfalls. J Oncol 2010, 2010:412985.

66. Isaacs JS, Jung YJ, Neckers L: Aryl hydrocarbon nuclear translocator (ARNT) promotes oxygen-independent stabilization of hypoxia-inducible factor-1alpha by modulating an Hsp90-dependent regulatory pathway. J Biol Chem 2004, 279:16128-16135

67. Qian DZ, Kato Y, Shabbeer S, Wei Y, Verheul HM, Salumbides B, Sanni T, Atadja P, Pili R: Targeting tumor angiogenesis with histone deacetylase inhibitors: the hydroxamic acid derivative LBH589. Clin Cancer Res 2006, 12:634-642.

68. Tacchini L, Dansi P, Matteucci E, Desiderio MA: Hepatocyte growth factor signalling stimulates hypoxia inducible factor-1 (HIF-1) activity in HepG2 hepatoma cells. Carcinogenesis 2001, 22:1363-1371

69. Koga F, Tsutsumi S, Neckers LM: Low dose geldanamycin inhibits hepatocyte growth factor and hypoxia-stimulated invasion of cancer cells. Cell Cycle 2007, 6:1393-1402

70. Kong D, Li Y, Wang Z, Banerjee S, Sarkar FH: Inhibition of angiogenesis and invasion by $3,3^{\prime}$-diindolylmethane is mediated by the nuclear factor-kappaB downstream target genes MMP-9 and uPA that regulated bioavailability of vascular endothelial growth factor in prostate cancer. Cancer Res 2007, 67:3310-3319.

71. Gopal U, Bohonowych JE, Lema-Tome C, Liu A, Garrett-Mayer E, Wang B, Isaacs JS: A novel extracellular Hsp90 mediated co-receptor function for LRP1 regulates EphA2 dependent glioblastoma cell invasion. PLoS One 2011, 6:e17649.

72. Andreasen PA, Egelund R, Petersen HH: The plasminogen activation system in tumor growth, invasion, and metastasis. Cell Mol Life Sci 2000, 57:25-40.

73. Sullivan $\mathrm{R}$, Graham $\mathrm{CH}$ : Hypoxia-driven selection of the metastatic phenotype. Cancer Metastasis Rev 2007, 26:319-331.

74. Xu K, Ding Q, Fang Z, Zheng J, Gao P, Lu Y, Zhang Y: Silencing of HIF1alpha suppresses tumorigenicity of renal cell carcinoma through induction of apoptosis. Cancer Gene Ther 2010, 17:212-222

75. Xie Q, Gao CF, Shinomiya N, Sausville E, Hay R, Gustafson M, Shen Y, Wenkert D, Vande Woude GF: Geldanamycins exquisitely inhibit HGF/SFmediated tumor cell invasion. Oncogene 2005, 24:3697-3707.

76. Kim LC, Song L, Haura EB: Src kinases as therapeutic targets for cancer. Nat Rev Clin Oncol 2009, 6:587-595.

77. Hauck CR, Hsia DA, Schlaepfer DD: The focal adhesion kinase-a regulator of cell migration and invasion. IUBMB Life 2002, 53:115-119.

78. Yano A, Tsutsumi S, Soga S, Lee MJ, Trepel J, Osada H, Neckers L: Inhibition of Hsp90 activates osteoclast c-Src signaling and promotes growth of prostate carcinoma cells in bone. Proc Natl Acad Sci USA 2008, 105:15541-15546.

79. Tang $\mathrm{CH}$, Wei $\mathrm{Y}$ : The urokinase receptor and integrins in cancer progression. Cell Mol Life Sci 2008, 65:1916-1932.

80. Palazzo A, Ackerman B, Gundersen GG: Cell biology: tubulin acetylation and cell motility. Nature 2003, 421:230.
81. Regan PL, Jacobs J, Wang G, Torres J, Edo R, Friedmann J, Tang XX: Hsp90 inhibition increases p53 expression and destabilizes MYCN and MYC in neuroblastoma. Int J Oncol 2011, 38:105-112.

82. Padua D, Zhang XH, Wang Q, Nadal C, Gerald WL, Gomis RR, Massague J: TGFbeta primes breast tumors for lung metastasis seeding through angiopoietin-like 4. Cell 2008, 133:66-77.

83. Nagy JA, Benjamin L, Zeng H, Dvorak AM, Dvorak HF: Vascular permeability, vascular hyperpermeability and angiogenesis. Angiogenesis 2008, 11:109-119.

84. Chatterjee A, Snead C, Yetik-Anacak G, Antonova G, Zeng J, Catravas JD: Heat shock protein 90 inhibitors attenuate LPS-induced endothelial hyperpermeability. Am J Physiol Lung Cell Mol Physiol 2008, 294:L755-763.

85. Antonov A, Snead C, Gorshkov B, Antonova GN, Verin AD, Catravas JD: Heat shock protein 90 inhibitors protect and restore pulmonary endothelial barrier function. Am J Respir Cell Mol Biol 2008, 39:551-559.

86. Chen L, Uchida K, Endler A, Shibasaki F: Mammalian tumor suppressor Int6 specifically targets hypoxia inducible factor 2 alpha for degradation by hypoxia- and pVHL-independent regulation. J Biol Chem 2007, 282:12707-12716

87. Koh MY, Darnay BG, Powis G: Hypoxia-associated factor, a novel E3ubiquitin ligase, binds and ubiquitinates hypoxia-inducible factor 1alpha, leading to its oxygen-independent degradation. Mol Cell Biol 2008, 28:7081-7095.

88. Fath DM, Kong X, Liang D, Lin Z, Chou A, Jiang Y, Fang J, Caro J, Sang N: Histone deacetylase inhibitors repress the transactivation potential of hypoxia-inducible factors independently of direct acetylation of HIFalpha. J Biol Chem 2006, 281:13612-13619.

89. Bendinelli $P$, Matteucci $E$, Maroni $P$, Desiderio MA: NF-kappaB activation, dependent on acetylation/deacetylation, contributes to HIF-1 activity and migration of bone metastatic breast carcinoma cells. Mol Cancer Res 2009, 7:1328-1341.

90. Kim SH, Jeong JW, Park JA, Lee JW, Seo JH, Jung BK, Bae MK, Kim KW Regulation of the HIF-1alpha stability by histone deacetylases. Oncol Rep 2007, 17:647-651.

91. Saito S, Lasky JA, Guo W, Nguyen H, Mai A, Danchuk S, Sullivan DE, Shan B: Pharmacological inhibition of HDAC6 attenuates endothelial barrier dysfunction induced by thrombin. Biochem Biophys Res Commun 2011.

92. Jain RK: Normalization of tumor vasculature: an emerging concept in antiangiogenic therapy. Science 2005, 307:58-62.

93. Niu G, Li Z, Cao Q, Chen X: Monitoring therapeutic response of human ovarian cancer to 17-DMAG by noninvasive PET imaging with (64) $\mathrm{Cu}$ DOTA-trastuzumab. Eur J Nucl Med Mol Imaging 2009, 36:1510-1519.

94. Chandarlapaty S, Scaltriti M, Angelini P, Ye Q, Guzman M, Hudis CA, Norton L, Solit DB, Arribas J, Baselga J, Rosen N: Inhibitors of HSP90 block p95-HER2 signaling in Trastuzumab-resistant tumors and suppress their growth. Oncogene 2010, 29:325-334.

95. Smith-Jones PM, Solit D, Afroze F, Rosen N, Larson SM: Early tumor response to Hsp90 therapy using HER2 PET: comparison with 18 F-FDG PET. J NuCl Med 2006, 47:793-796.

96. Smith-Jones PM, Solit DB, Akhurst T, Afroze F, Rosen N, Larson SM: Imaging the pharmacodynamics of HER2 degradation in response to Hsp90 inhibitors. Nat Biotechnol 2004, 22:701-706.

97. Niu G, Cai W, Chen K, Chen X: Non-invasive PET imaging of EGFR degradation induced by a heat shock protein 90 inhibitor. Mol Imaging Biol 2008, 10:99-106.

98. Kim YS, Alarcon SV, Lee S, Lee MJ, Giaccone G, Neckers L, Trepel JB: Update on Hsp90 inhibitors in clinical trial. Curr Top Med Chem 2009, 9:1479-1492.

\section{Pre-publication history}

The pre-publication history for this paper can be accessed here: http://www.biomedcentral.com/1471-2407/11/520/prepub

\section{doi:10.1186/1471-2407-11-520}

Cite this article as: Bohonowych et al:: Comparative analysis of nove and conventional Hsp90 inhibitors on HIF activity and angiogenic potential in clear cell renal cell carcinoma: implications for clinical evaluation. BMC Cancer 2011 11:520. 